\title{
Difficult bile duct cannulation: Do all roads lead to Rome?
}

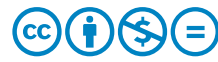

\author{
Author \\ Marianna Arvanitakis \\ Institution \\ Erasme University Hospital, Brussels, Belgium \\ Bibliography \\ Endosc Int Open 2021; 09: E1768-E1769 \\ DOI 10.1055/a-1591-1044 \\ ISSN 2364-3722 \\ (C) 2021. The Author(s). \\ This is an open access article published by Thieme under the terms of the Creative \\ Commons Attribution-NonDerivative-NonCommercial License, permitting copying \\ and reproduction so long as the original work is given appropriate credit. Contents \\ may not be used for commercial purposes, or adapted, remixed, transformed or
}

\author{
built upon. (https://creativecommons.org/licenses/by-nc-nd/4.0/) \\ Georg Thieme Verlag KG, Rüdigerstraße 14, \\ 70469 Stuttgart, Germany \\ Corresponding author \\ Marianna Arvanitakis, Department of Gastroenterology, \\ Erasme University Hospital, Route de Lennik 808, 1070 \\ Brussels, Belgium \\ Fax: +3225554697 \\ marianna.arvanitaki@erasme.ulb.ac.be
}

Successful selective biliary cannulation is an undisputable prerequisite for offering successful therapy during endoscopic retrograde pancreatography (ERCP) [1]. Numerous potential determinants for successful native papilla cannulation have been identified, including endoscopist experience, anatomy of the papilla (size, morphology, or orientation), and anatomical variants, such as presence of a large diverticulum or surgically altered anatomy [2]. The European Society of Gastrointestinal Endoscopy suggests that difficult biliary cannulation is defined by the presence of one or more of the following: more than five contacts with the papilla while attempting to cannulate; more than 5 minutes spent attempting to cannulate following visualization of the papilla; and more than one unintended pancreatic duct cannulation or opacification [2]. Difficult cannulation is widely accepted as being a risk factor for post-ERCP acute pancreatitis (PEP) [2]. Both rates of successful biliary cannulation and PEP are considered performance measures with respective thresholds of $>90 \%$ (target $>95 \%$ ) and $<10 \%$ (target $<5 \%$ ) [1].

In case of failure of standard cannulation methods, alternative techniques have been described, such as the pancreatic guidewire-assisted technique (PGW), needle-knife precut or fistulotomy, and transpancreatic biliary sphincterotomy (TPS) [2]. Choosing from the above methods depends on many factors, such as the presence or not of an unintentional pancreatic guidewire insertion, anatomy of the papilla (small vs bulging) and the expertise of the operator. In any case, prevention of PEP is strongly recommended with rectal nonsteroidal anti-inflammatory drugs (NSAIDS) in all patients without contraindications, as well as with insertion of a prophylactic pancreatic stent in high-risk patients, after inadvertent guidewire insertion/opacification of the pancreatic duct or use of the PGW or TPS techniques [3].
In this issue of Endoscopy International Open, Guzman-Calderon et al describe a systemic review and meta-analysis comparing two techniques used during difficult cannulation, PGW and TPS [4]. They identified four randomized controlled trials (RCTs) including 260 patients [5-8]. In 134 patients (51.5\%) TPS was performed, and in 126 (48.5\%) PGW. The authors concluded that whereas there was no significant difference in successful cannulation rate, overall adverse event (AE) rate, and mean of cannulation time, the PEP rate was lower in patients who underwent TPS than in patients who underwent PGW (TPS: $8.9 \%$ vs PGW: $22.2 \%, P=0.020$, RR $=0.47$, $95 \% \mathrm{Cl}[0.25-$ $0.89]$ ] [4]. Regarding the quality of the studies included, although heterogeneity was low, the overall risk of bias was considerable, especially for measurements of outcome. Finally, the authors concluded that although both techniques can be used, if performed by operators with the required experience, TPS seems to have a lower rate of PEP.

Both TPS and PWG require insertion of a guidewire in the pancreatic duct. During PWG, the guidewire helps in straightening the anatomy and facilitating navigation of the second guidewire within the S-shape of the distal common bile duct. On the other hand, TPS consists of passing a sphincterotome over the guidewire previously inserted in the main pancreatic duct and performing a septotomy in the direction of the bile duct (11-12 o'clock) to obtain a septotomy. Whereas the former respects the anatomical landmarks, the latter involves blindly cutting through the septum. Therefore, it would be expected that TPS would have a higher AE rate. The current study shows reassuring data regarding the safety of TPS and potentially moving it a step up as a one of the methods of choice in case of difficult cannulation. 
Moreover, the authors concluded that TPS had a lower rate of PEP than PWG. As regards this specific outcome measure in the included RCTs, the lack of systematic use of PEP preventive measures represents a major caveat. This could explain the relatively high overall rate of AE. There is no reference to rectal NSAIDS, and only one study reports prophylactic pancreatic stent insertion in all patients [7]. Interestingly, PEP rates were very low in the aforementioned study ( $2.9 \%$ in both groups) [7]. Therefore, both techniques probably have the same safety profile if the required preventive measures are taken to avoid PEP.

In conclusion, the current work offers additional data promoting the use of both TPS and PWG for difficult cannulation. TPS could be considered at the same timepoint during biliary cannulation as PWG, when there is an unintentional pancreatic duct guidewire insertion. Nevertheless, similar to needle-knife precut, expertise is still a prerequisite for TPS [2], as a poorly performed septotomy can increase the risk of AEs and impede future cannulation maneuvers. Finally, all endoscopists performing ERCP should strive to improve by keeping track of major performance measures, notably cannulation rate and PEP rate [1]. All roads may lead to Rome, but they should provide a safe journey.

\section{Competing interests}

The authors declare that they have no conflict of interest.

\section{References}

[1] Domagk D, Oppong KW, Aabakken L et al. Performance measures for ERCP and endoscopic ultrasound: a European Society of Gastrointestinal Endoscopy (ESGE) Quality Improvement Initiative. Endoscopy 2018; 50: 1116-1127

[2] Testoni P, Mariani A, Aabakken L et al. Papillary cannulation and sphincterotomy techniques at ERCP: European Society of Gastrointestinal Endoscopy (ESGE) Clinical Guideline. Endoscopy 2016; 48: 657-683

[3] Dumonceau JM, Kapral C, Aabakken L et al. ERCP-related adverse events: European Society of Gastrointestinal Endoscopy (ESGE) Guideline. Endoscopy 2020; 52: 127-149

[4] Guzmán-Calderón E, Martinez-Moreno B, Casellas JA et al. Transpancreatic precut papillotomy versus double-guidewire technique in difficult biliary cannulation: a systematic review and meta-analysis. Endosc Int Open 2021; 09: E1758-E1767

[5] Cha S, Kim S, Kim A et al. DGT vs TPS in patients with initial pd cannulation by chance; prospective randomized multi-center study. Gastrointestinal Endoscopy 2012; 75: AB141

[6] Yoo YW, Cha SW, Lee WC. Double guidewire technique vs transpancreatic precut sphincterotomy in difficult biliary cannulation. World J Gastroenterol 2013; 19: 108-114

[7] Sugiyama H, Tsuyuguchi T, Sakai Y et al. Transpancreatic precut papillotomy versus doubleguidewire technique in difficult biliary cannulation: prospective randomized study. Endoscopy 2018; 50: 33-39

[8] Mohie E, Mohamed A, Al-Sisi M. Double guidewire technique versus transpancreatic sphincterotomy for difficult biliary cannulation. Egyptian J Hosp Med 2019; 74: 764-770 